\title{
Experiments, Mathematics and Principles of Natural Philosophy in the Epistemology of Giovanni Battista Baliani
}

\author{
Danilo Capecchi \\ Dipartimento di Ingegneria Strutturale e Geotecnica, Sapienza University of Rome, Rome, Italy \\ Email: danilo.capecchi@uniroma1.it
}

How to cite this paper: Capecchi, D. (2017). Experiments, Mathematics and Principles of Natural Philosophy in the Epistemology of Giovanni Battista Baliani. Advances in Historical Studies, 6, 78-94. https://doi.org/10.4236/ahs.2017.62006

Received: March 2, 2017

Accepted: June 18, 2017

Published: June 21, 2017

Copyright $\odot 2017$ by author and Scientific Research Publishing Inc. This work is licensed under the Creative Commons Attribution International License (CC BY 4.0).

http://creativecommons.org/licenses/by/4.0/ (c) (i) Open Access

\begin{abstract}
The epistemology of Giovanni Battista Baliani, a leading 17th century Italian scientist, is the focus of this article. In his treatise on motion, De motu naturali gravium solidorum (1638), Baliani's epistemology was grounded on empirical principles-the law of the pendulum essentially-in the footsteps of the "old" mixed mathematics. In a new edition, De motu naturali gravium solidorum et liquidorum (1646), Baliani changed his approach and grounded his epistemology on principles of natural philosophy with a metaphysical and not empirical evidence. An analysis of Baliani's writings reveals a tension between his empiricist philosophy, which he maintained throughout his life, and his mathematical approach, which was still based on experience; but on an experience derived from measurements and intrinsically affected by errors, it was hence uncertain. A comparison with Galileo's epistemology is also made to better understand trends in mathematical physics at the end of the 1600's.
\end{abstract}

\section{Keywords}

History of Mechanics, Impetus Theory, Mixed Mathematics, Epistemology

\section{Introduction}

Giovanni Battista Baliani (1582-1666), the son of a senator, was trained in the law and spent most of his adult life in public service. His scientific interests date to 1611 when he was prefect of the fortress at Savona. There he noted how cannon balls of different weights fall at the same speed, or so he says. In 1613 Filippo Salviati (1582-1614) met Baliani and wrote about him to Galileo (Galilei, 1890: vol. 11, p. 610), thus, began a correspondence between the two concerning the experimental determination of the weight of air. In 1615 Baliani visited Galileo in Florence and also met Benedetto Castelli (1578?-1643). The intermittent 
correspondence with Galileo that lasted until 1639 shows Baliani to have been a talented experimentalist and an ingenious speculator. In 1630 he wrote to Galileo describing the failure of a siphon to lift water more than ten meters. Baliani blamed the atmospheric pressure for this, but expressed uncertainty regarding whether the total weight of a column of air many kilometers high was less than that of a ten meter column of water, at which height Galileo had already noted the failure of sucking pumps.

In astronomy, although Baliani preferred Tycho Brahe's system to that of Copernicus, he speculated on the possibility of tides being caused by terrestrial motion. In 1632 in Genoa, Baliani met the Jesuit philosopher Niccolò Cabeo (15861650) forming a lasting friendship. Baliani returned to Savona in 1647 as governor, a post he held until 1649. He was then elevated to membership of the principal governing body of Genoa, where he remained until his death.

In 1638 Baliani published the short treatise, the De motu naturali gravium solidorum (Baliani, 1638), that preceded the publication of Galileo's Discorsi e dimostrazioni matematiche of the same year. Both the content and conclusions were similar, but no one at the time accused Baliani of plagiarism, though Galileo believed that he had not been cited adequately. Baliani's treatise was wellreceived and circulated widely even outside of Italy (Moscovici, 1967: pp. 18-21). The 1638 edition was followed by a second enlarged edition in 1646, the De motu naturali gravium solidorum et liquidorum (Baliani, 1646). In 1647 Baliani published a treatise on natural philosophy, entitled Trattato di Gio. Battista Baliano della pestilenza (Baliani, 1653) ${ }^{1}$. In this work he also stated the principle that population increase was related to the availability of arable land and food production would necessarily result in famine were it not for the occurrence of war and pestilence. The quantitative nature of his argument entitles him to be regarded as a predecessor Malthus (Drake, 1967: pp. 401-402). Baliani's Trattato appeared shortly after the publication of an important text on a pseudo-Aristotelian philosophy of nature by his friend Cabeo (Cabeo, 1646).

Baliani's influence on other contemporary scientists was less than it should have been. This is mainly because he was an amateur in the field, moreover, Genoa and Liguria were not very receptive to matters of culture (Lavaggi, 2004: pp. 93-115), and his opposition to Galileo did not make him popular with contemporary scientists. For reasons not covered here, his stance against Galileo most certainly and unjustly compromised his cultural (and moral) credibility (Baroncelli, 1998). This apart, in the middle of the 17 th century he actively participated in the international debate on various issues regarding mechanics (modern meaning). Baliani probably did not arrive at the laws of falling bodies independently of Galileo, but he was the first to introduce the substantially modern concept of inertial mass. His correct conception of atmospheric pressure remained unpublished, although Torricelli may have been aware of it from Galileo. Baliani's most important contribution, the discussion on elastic shock,

${ }^{1}$ I had no access to the 1647 edition so referenceis to Giovanni Battista Baliani, Trattato di Gio. Battista Baliano della pestilenza: ove si adducono pensieri nuovi in più materie (Genova, 1653). 
seems to have gone unnoticed until quite recently (Moscovici, 1967; Costantini, 1969; Baroncelli, 1998; Savelli, 1953; Drake, 1967: pp. 401-402; Maffioli, 2011: pp. 73-104; Moscovici, 1960; Moscovici, 1965; Nonnoi, 1988; Raymond Zouckermann, 1982; Capecchi, 2013; Capecchi, 2014; Capecchi, 2015; Somaglia, 1983).

Serge Moscovici in 1967 was the first to analyse in depth the work of Baliani and restore some credibility to the scientist (Moscovici, 1967). Claudio Costantini in 1969 analysed Baliani's philosophical conceptions and the reactions of Jesuit scholars to the publication of Baliani's treatises (Costantini, 1969). Giovanna Baroncelli in 1998 translated into Italian the De motu naturali gravium solidorum et liquidorum, with a meagre but quite accurate comment (Baroncelli, 1988).

Baliani, however, in my opinion, deserves greater focus and the scope of this study is to further our knowledge of his contribution to science. Attention is centred on Baliani's empirical epistemology that has received very little attention in the literature. His position on this point is very interesting as it casts light on the transition from the old approach to mixed mathematics in the Renaissance, largely biased by Aristotelian epistemology and involving only a few aspects of natural philosophy, to modern mathematical physics that attempts to embrace all the natural philosophy of inanimate beings. It may also further an understanding of Jesuit epistemology recently the focus of renewed interest (Dear, 1995).

The following aspects will be examined:

1) Relations among Baliani's natural philosophy, mathematics and empirical observations.

2) Trends from 1638 to 1646.

3) A comparison between Baliani's and Galileo's approach to mixed mathematics.

\section{The De Motu Naturali Gravium Solidorum, 1638}

The De motu naurali gravium solidorum of 1638, opened with a preface where Baliani talked about his experience with falling bodies since 1611. In particular, he stated to have verified that the speed of a falling body, or rather the time taken to fall from a fixed height, is independent of the weight of the body, thus claiming his priority over Galileo. He also made reference to pendulums of constant length, where the periods were found to be independent of the weights.

Baliani adopted a mixed mathematics approach where merging information acquired through experience and mathematical deduction was typical. In essence, the scholar of the mixed mathematics waives the search for the ultimate causes, especially efficient causes, to settle for more proximate causes and offer a simpler explanation of complex phenomena.

I premised some of the principles of nature, because I cannot see how otherwise to deduce the conclusions. I decided to call hypotheses (suppositiones) those [propositions] that derive from the mentioned experiments and to separate them from the other postulates (petitiones). I considered 
appropriate to ignore geometric postulates as they are easy to understand and thus superfluous (Baliani, 1638: pp. 5-6)'

The hypotheses assumed by Baliani are the observations confirmed by repeated experiences (Baliani, 1638: p. 5), reported below:

1) Equal vibrations of equi-pendulums of any weight are equi-periodic.

2) Even if unequal, the vibrations of equi-pendulums are equi-periodic.

3) The lengths of pendulums with unequal lengths are in duplicate proportion with the periods of vibrations, that is as their squares.

4) Moment for a heavy body over an inclined plane is to its heaviness as the vertical is to inclined lines (Baliani, 1638: p. 8).

The first three hypotheses appear in the form announced by Baliani; they could possibly be deduced from experimental observation of the pendulum ${ }^{3}$. The statement of the first hypothesis for which the period of oscillation is independent of the weight of the bob is justified here on an experimental basis. However, Baliani could also justify this on a metaphysical basis. In the preface he wrote:

I resolved to assign the role of the agent to gravity, and to matter, or if you prefer the material body, that of the patient, and therefore estimate that heavy bodies move according to the proportion between gravity and matter, consequently, as long as they move naturally along the vertical line without any impediment, they move equally, given that greater matter or material quantity corresponds to greater gravity (Baliani, 1638: 4)

Thus, because of the balance of the activity of gravity and the passivity of matter, both proportional to the quantity of matter, all bodies fall at the same speed, independently of weight.

The fourth hypothesis is quite different from the others and the status Baliani attributed to it seems quite unjustified. It does not express an empirical observation and introduces a concept crucial to Baliani, that of moment, as the inclination to motion of bodies due to active actions. This is assumed here to be proportional to the gravity of the body and the slope (ratio between height and length) of the plane ${ }^{4}$.

Other assumptions referred to by Baliani simply as postulates (petitiones) are as follows:

1) Similar portions of vibration of pendulums are to each other, regarding the period, as the whole vibrations.

2) Moments of heavy bodies are to each other as their speeds.

3) The minimal portions of a circle are similar to straight lines.

4) Given a straight line segment, we can conceive a circle so great that its arc, which in the opinion of the senses is equal to the assigned segment, could be as-

\footnotetext{
${ }^{2}$ This quotation and all the remaining are translated into English by the author. ${ }^{3}$ For a modern reader, it is easy to criticize Baliani's hypotheses as it is now known that the oscillations of pendulums are not synchronous. However, then, the situation was different; in particular Galileo himself was convinced of the isochronism. Among the supporters of the opposite thesis we find Mersenne and Descartes. See for instance (Matthews, 2000: p. 177).

${ }^{4}$ Baliani attributed hypothesis 4 to both Galileo and Stevin (Baliani, 1638: p. 5).
} 
similated to a straight line.

5) In free fall vertical motion, solids move with equal speed, and according to the proportion observed by pendulums that describe the first portion of the vibrations.

6) In natural motion along an inclined plane, solids move with equal speed and as if they were pendulums that describe that portion of vibrations that according to the judgment of the senses is equal and parallel to the line of the plane on which the said solids move (Baliani, 1638: pp. 10-12).

It is hard to see any difference in status between some of the postulates and the hypotheses, apart from the third and fourth, that are geometrical in nature. For the other postulates the difference is only due to their lower evidence.

Baliani derived twenty-seven theorems and problems (propositiones) from his hypotheses and postulates. The most interesting of these is propositio 3, from which the law of square times is derived (Baliani 1638: p. 14). The third hypothesis is crucial here. Using this the following law can be easily deduced: the space covered by a heavy body appended to a pendulum is in duplicate proportion with the time taken. Indeed, the space covered is proportional to the length of the pendulum, which in turn is in duplicate proportion with its period, that is the time taken for a full oscillation. However, the same ratio is maintained for any partial small oscillation (postulate 1), and thus also for a small oscillation starting from the horizon (pendulum at $90^{\circ}$ ). This small oscillation, nonetheless, can be confused with a small vertical motion (postulates 4 and 5), hence the law of square time for the free fall. In proposito 6 , the law of odd numbers is immediately proved (Baliani 1638: p. 17). Some historians underline the weakness of some of Baliani's proofs. This aspect is not relevant to this study and the interested reader can refer to the literature ${ }^{5}$.

\section{Galileo's Reception}

Galileo, in his correspondence, even though he agreed in principle with Baliani's approach, denied the possibility of using principles such as those chosen that seem too complex to enjoy the seal of certainty. In particular Galileo did not appreciate the postulate where the initial part of the motion of a pendulum, moving from the horizontal position, is the same as that occurring in a free vertical fall:

It is our intention to investigate and prove geometrically accidents and passions, which occur to heavy movables, naturally and freely descendants over rectilinear spaces, different or by length or by tilt, or by both together. Then in the choice of principles, on which science must be founded, you take as fair notice, some accidents, which have no connection with motions made above lines that are not straight, nor of assignable inclination, nor that in these the different lengths operate as they do in straight lines, but in all respects, are very different things, what looks a serious mistake to me, even

${ }^{5}$ See for instance (Moscovici 1967: Chapter 1); (Baroncelli, 1998: Introduction); (Capecchi, 2014: Chapter 4). 
more so as it drags along another no lesser [mistake] (Caverni, 1891: vol. 4, p. 313$)^{6}$.

Galileo considered "very hard" the assumption of confusing the vertical motions of a free body with the beginnings of the motion of a pendulum:

Very hard is the assumption, as we shall say hereinafter, that the motions for minimal parts of the arcs are as if they were for straight lines, assumption as I say very hard, thus the reader may ask with reason that the amount of arc, that V. S. called minimum, is such even to him, so that, for example, you intend the arc to be minimal if it is under one half of a degree. Furthermore, it would have been necessary to declare which of the straight lines should be taken for the minimum arcs, that is, that, which, departed from the same point of the arc touches the circumference, or as a cord of the minimal arc, or one of many others, that can be drawn from the same first point (Caverni, 1891: vol. 4, pp. 313-314).

and proposed an alternative proof that, in my opinion, was not very convincing (Capecchi, 2014: pp. 190-191). Galileo somewhat provocatively declared the empirical verification to be irrelevant.

But coming back to my treatise of motion, I argue ex suppositione on motion, defined in that way, so although the consequences do not respond to the accidents of natural motion of falling heavy bodies, it is of little matter to me, since nothing deviates from Archimedes' demonstration, not being in nature any heavy body that moves into spiral lines. But in this I have been, so to speak, lucky, since the motion of heavy bodies and its accidents promptly respond to the accident I demonstrated about the motion I defined (Galilei, 1890: vol. 18, pp. 12-13).

Baliani did not agree and replied ${ }^{7}$ :

I thank V. S., also for the patience you had in reading my writings and the considerations that you made. I actually judged that experiences are to be assumed as the principles of sciences, when they are sure, and that from the things known to the senses science leads us towards a knowledge of the unknown [...] and that the search for the cause is the object of another source, namely wisdom, as I mentioned in the preface of the book on Motions [De motu naturali gravium solidorum], and as the principles of science should be definitions, axioms, and petitions, which in these natural things are mostly experience, and astronomy [emphasis added], music, mechanics, perspective, and all the rest are based on this (Galilei, 1890: vol. 18, p. 69).

Galileo's objections are emphasised and uncritically subscribed to by some

${ }^{6}$ Here Caverni refers to a lost letter from Galileo to Vincenzo Renieri (1606-1647), reported by Vincenzo Viviani.

${ }^{7}$ Baliani's reply is not to Galileo's letter of 7th January 1639, but to a Galileo's lost letter of 20th June 1639; (Moscovici, 1967: p. 141). 
historians of science ${ }^{8}$. While I can accept Galileo's claims for which some of Baliani's postulates were all but evident at the time, I cannot accept other historians' criticisms of Baliani whose approach they believe was less interesting than that of Galileo, especially when this judgement pretends to be based on the achievements of the modern (Newtonian) mechanics. A modern mathematician or physicist will find Baliani's approach quite clever and simple. The law of square time is transferred from an ambit where it could be easily verified, to an ambit where it was nearly impossible to carry out reliable measurements. Any modern mathematician will accept the postulate for which the motion on straight lines could be assimilated to that on curves ones'. Even the hypothesis that the oscillations of the pendulum are not isochronous-which some historians anachronistically assume as a limit on the part of Baliani-does not falsify the law of square times ${ }^{10}$. The doubt thus could be raised that Galileo's objections to Baliani were partly due to his self-seeking desire to defend the priority and superiority of his own approach.

A fundamental difference can be noted between the empirical approaches of Baliani and Galileo. Baliani followed the epistemology shared by Aristotelian philosophers for mixed mathematics. They assumed as principles of a science some empirical statements, which were judged sure, though not logically necessary; the mixed mathematics (sciences) of reference could be optics and science of weights. Differently from these sciences, where the empirical principles were derived from every day experience, such as for instance the fall of heavy bodies, in Baliani's science principles were empirical laws derived from repeated experiments carried out in laboratories using measuring instruments such as clocks and graduated rules. Galileo instead assumed as a hypothesis a congectural principle, the proportionality of speed and time, which is suggested neither by every day experience nor by a laboratory. The mixed science of reference here is astronomy, in the footsteps of Ptolemy, who assumed the hypotheses of eccentrics and epicycles, which in no way could directly be gathered from observational astronomical data ${ }^{11}$. According to this approach the hypothesis is accepted (considered true) if it fits with the observations.

The particular role Baliani attributed to epistemology of astronomy is clearly exemplified in the Dialogo secondo of his Operediverse (Baliani, 1666). Here astronomy is considered as the example of conjectural knowledge to confront with certain knowledge. In the Dialogo, Baliani asserted that there are three routes to proceed towards knowledge:

The first when, once the effects are known, it is recognized that there are

\footnotetext{
${ }^{8}$ See for instance (Moscovici, 1967: pp. 32-36).

${ }^{9}$ Cavalieri seemed to appreciate Baliani's mathematical approach (Baliani, 1792: pp. 34-35).

${ }^{10}$ It can be shown that for a fixed angular amplitude the period of oscillation is still proportional to the square root of the length of the pendulum. The constant of proportionality however depends on the angular amplitude.

${ }^{11}$ The similarity of the approaches of Galileo and Ptolemy is suggested for instance in: (Drake, 1978); (De Pace, 1993: pp. 318-336).
} 
causes for them, though unknown. The second when a thing is imagined and it is recognized that if it were true, effects would necessarily occur. The third when from known and not imagined things it is recognized that effects necessarily occur (Baliani 1666: p. 53).

The first route towards knowledge is the most simple, but it is incomplete. Regarding the second route Baliani referred to Democritus' atomism, Aristotle's hylomorphism and astronomy:

I suppose it [the second route towards knowledge] is when philosophers, imagining either atoms of matter and form in the world, believe that from these necessarily derives all what their sense suggests [...]. I estimate this is a form of knowledge of causes of natural effects, similar to how astronomers explain heavenly motions by imagining epicycles in the heavens, of which they have no sensible knowledge, and maintain that, if they existed, heavenly motions would occur such those the sense represents to us (Baliani, 1666: p. 54).

The third route towards knowledge that starts directly from empirical experience, and thus of which there are NO doubts, is that used by Baliani in the De motu naurali gravium solidorum.

The first "modern" writer to stress the difference between Galileo and Baliani, to my knowledge, is the Jesuit Vincenzo Riccati in his letter to Salvatore Corticellio:

Galileo's method, if I well understood, follows this approach $[\ldots]$ he puts before the congruous hypothesis according to which for equal small times equal degrees of speed are acquired [...] this hypothesis cannot be judged at the moment as true, but is considered as a proposed cause that can be the object of analysis and subjected to experience. [...] I pass now to Baliani's method, whose reasoning starts from experience, which in mathematical physical investigations should be considered both as a unique and universal principle (Riccati, 1757: p. 139).

Riccati, substantially faithful to the Aristotelian epistemology of the Jesuits, expresses his preference for Baliani's approach:

Galileo whose prudence, by submitting his hypothesis to experiment, is to be praised, but Baliani's methods are more exact and apt, in my opinion (Riccati, 1757: p. 140).

Since 1632, in a letter dated 23rd April, Baliani had begun to question Galileo about the possibility of experimental measurements of the law of falling bodies (Galilei, 1890: vol. 14, pp. 343-344). The problem seems to be not so much if the falling bodies follows the law of odd numbers, or if they move with space in duplicate proportion with time but, rather, to precise quantitatively the law (Koyré, 1953); for instance to respond the question: in how many seconds will it take to pass through a given space? The experiment that Galileo is said to have per- 
formed, was not convincing ${ }^{12}$. Baliani realized that the main difficulty was to find an accurate clock, and he identified this clock in a simple pendulum that can beat the second ${ }^{13}$. Moscovici summarises the events that eventually led to the definition of this pendulum. First, confirm that you have the correct template for your paper size. This template has been tailored for output on the custom paper size $(21 \mathrm{~cm} \times 28.5 \mathrm{~cm})$.

\section{The De Motu Naturali Gravium Solidorum and Liquidorum of 1646}

In 1646 Baliani published a new enlarged edition of his book, entitled De motu naturali gravium solidorum and liquidorum. At a first glance the main difference between the two editions is that the later edition is much longer; five additional books were added. The first book was nearly the same as the 1638 volume, with a few substantial corrections (Baroncelli, 1998). The second book contained what, to my opinion, is the most important technical achievement of the treatise; in propositio 3 Baliani showed that impetus (speed) increased proportionally with time. Thus, he inverted Galileo's approach. Galileo, from the proportionality of speed and time had derived the law of square times (in modern terms he carried out an integration); Baliani from the law of square times derived the proportionality of speed and time (in modern terms he carried out a derivative). The third book of Baliani's treatise dealt with the motion of bodies over inclined planes; the remaining books concerned fluids, a subject which Baliani had long doubted could be treated with the same laws of falling bodies, as testified by the correspondence with Castelli (Cardinali, 1823).

Also the epistemological approach was overturned. According to Baliani the science of motion could no longer be based on empirical principles, but, rather on principles of natural philosophy. Based on these principles, he arrived at a law of motion that contradicted that of 1638 . Then falling bodies followed the law of odd numbers, now that of natural numbers. Baliani noted that these two laws if well interpreted differed only slightly, and are indistinguishable basing on experiments, but it was the first to be merely approximate. Hence the conclusion: one cannot decide the correctness of a law only on the basis of experience, which can be deceiving. Thus a physical law must be deduced from general principles of natural philosophy not grounded on experience.

Of course, one wonders what had produced this change and why Baliani, who until then had behaved essentially as a mathematician, edged nearer to the philosophy of nature. Biographical information on Baliani and his correspondence are little known, so one can only guess.

Any hypothesis, however, should take into account the following two points:

${ }^{12}$ For instance, Galileo in his Dialogosoprai due massimisistemi declared that a heavy body will pass 100 braccia in 5 seconds, in a free fall (Galileo, Opere, vol. 7, p. 250). Assuming that 1 braccio is about $0.55 \mathrm{~m}$ (this is a current estimate), the acceleration of gravity (modern term) would be about $4.5 \mathrm{~m} / \mathrm{s}^{2}$, much lower than the true value $\left(9.8 \mathrm{~m} / \mathrm{s}^{2}\right)$ and of the value found by other experimentalists such as Mersenne, for example (Koyré, 1953).

${ }^{13}$ Letter to Galileo 19th August 1639 (Galile1, 1890: vol. 18, p. 87). 
1) Baliani, as illustrated in the next section, already showed an interest in natural philosophy before 1638 and maintained throughout his life the same empiricist position: for proven and not conjectural knowledge, philosophy should be based on principles that are immediate consequences of empirical observations.

2) Baliani knew the impetus theory by his contact with Fabri, who in 1646, the same year as the publication of the De motu naturali gravium solidorum et liquidorum, published the Tractatus physicus de motu locali, very close to Baliani's treatise in the use of the concept of impetus. Baliani's contact with Fabri is only documented after $1646^{14}$, apparently too late to justify any influence. Considering however that, notwithstanding the official date of publication, Baliani's treatise was actually published only in 1647 (Galluzzi, 2001: p. 267), there would have been time to produce all the necessary changes to the text.

On the basis of these considerations, I believe that there are substantially only two hypotheses to justify the apparently irrational stance on Baliani's part.

1) Baliani was sincerely attracted by the impetus theory and adopted it despite the contraposition with his empiricist theory of knowledge. Perhaps he hoped, to solve the conflict later, although there is no documentation with regard to this.

2) Baliani strongly wished to establish his originality and priority over Galileo. His implementation of the impetus theory, besides expressing its own originality, showed that Galileo's law of falling bodies was wrong and challenged his (Galileo's) epistemological approach. This thesis is an adjustment of that proposed by (Costantini, 1969) and (Galluzzi, 2001), who also assumed socio-political reasons, connected to Baliani's contact with Jesuit scientists (besides Cabeo and Fabri, also Orazio Grassi at least). Baliani would have been convinced by the Jesuits to contrast Galileo and the change in his epistemological position would have been simply a pretext.

\section{Baliani's New Epistemology}

Baliani's epistemological positions are reported as a premise in each of the six books of the second edition. First he declared that he was following in the footsteps of mixed mathematics, music, mechanics and optics:

So far I have dealt according to my ability with the science of natural motion of solids, arguing and making manifest many of their unknown characteristics from some properties known to the senses. In only this, moreover, any science consists, at least according to Aristotle and the practice by which it can be deduced from the work of Euclid and those involved in pure science, according to which it is not the responsibility of the Geometer to investigate the nature of the quantity, nor the musician that of sound, nor the student of perspective the nature of the light, nor the mechanic the essence of weight (Baliani, 1646: p. 97).

Note he did not mention astronomy, and this cannot be by chance if one re-

${ }^{14}$ Contacts between Baliani and Fabri are documented by Baliani's correspondence with Grassi (Moscovici, 1967: pp. 256-261), with Mersenne and of Mersenne with Fabri's pupil, Pierre Mousnier (Galluzzi, 2001: p. 267). 
calls the previous section of the present paper ${ }^{15}$. He was however not satisfied by the empirical evidence and wanted to deal with the first causes, for which he could equally refer to Aristotle:

However, my mind is not satisfied, I do not say if it does not understand completely, but even if it does not investigate the first causes from which these effects derive, looking for the nature of mobile, or the bodies as movable, even though this examination does not concern the science of motion, but a higher level of wisdom, through which we arrive not so much at the effects but at the essence and the principles of things (Baliani, 1646: pp. 97-98).

Baliani maintained he could find a physical foundation for the law of falling bodies, that is the first causes of motion, with two principles of natural philosophy, which he considered incontestable. The first principle concerned the passivity of matter and the activity of gravity-considered as an action or virtue, which acts continuously and regularly — and that balance each other. Thus, if one imagines time divided into small constant intervals, gravity/passivity always causes the same downward displacement in each of these intervals as the same cause must produce the same effect.

The second principle was that of the preservation and accumulation of the impetus, a word and a concept not used in the 1638 edition. Impetus is generated by gravity in each interval $\Delta t$, and its function is to maintain constant the acquired motion. This second principle is nothing but a revival of the medieval theory of impetus from the school of Jean Buridan.

For many years now, I think I have penetrated the cause of the acceleration of motion, in the case in which the movable is constantly pushed by an engine; while in motion, in fact, an impetus is impressed in the movable which in turn causes the subsequent motion, for which in the second interval of time there are two engines, which make the motion faster and the impetus greater, in a third interval there are still both engines, but as the impetus is different, and stronger, the motion is even faster, and so on within the following intervals. [...]. These considerations suggested to me the idea that the essence of the mobiles is indifferent either to rest or movement, so that, whenever it is given a movement, and whatever cause it comes from, natural or violent, a similar movement follows, or the same movement of before perseveres, at the same speed that it had assumed at any instant, until it is not constrained (Baliani, 1646: pp. 99-101).

With these two principles it is easy to find/explain the motion of falling bodies. The first principle allows a proof that all bodies fall with the same speed (in the void). The second principle furnishes the temporal law of the fall.

To obtain the temporal law Baliani considered a sequence of time intervals $\Delta t$; in the first time interval there is a displacement $\Delta s$ due to gravity that generates a certain speed and a certain impetus. In the second time interval there is still a

${ }^{15}$ To note that in the already quoted letter to Galileo, 1 July 1639, Baliani listed the components of mixed mathematics, including astronomy. 
displacement $\Delta s$ due to gravity and another displacement that Baliani assumed equal to $\Delta s$, due to the impetus associated with the speed acquired at the end of the interval $\Delta t$. In total there is therefore a displacement of $2 \Delta s$. In the third interval there is a displacement $\Delta s$ due to gravity and a displacement $2 \Delta s$ due to the impetus acquired at the end of the second time interval, equal to the sum of the impetus acquired in the first interval and that acquired in the second interval, thus arriving at a displacement $3 \Delta s$. Going forward with the other intervals a progression of spaces is generated which follow that of natural numbers.

At this point Baliani realized that the law that he had derived from 'indubitable' physical principles was not in agreement with the law he had derived from the 'indubitable' empirical principles he had assumed in the 1638 edition, according to which the fall of bodies followed the time squares and hence the progression of odd numbers. He did not seem embarrassed by this fact and postulated, showing himself to be a discrete mathematician, that the law of natural numbers, for very small time intervals, or equivalently a large number of intervals, approximates that of odd numbers. So, of course, there was a discrepancy between experience and theory, but this discrepancy, although not eliminable, could be made small at will. And the defect for Baliani is in the experiment that cannot yield results with the due precision:

Though not being completely exact, indeed such a [experimental] law is so close to the true one to be indistinguishable from it to the judgement of sense and the scrutiny of accurate and targeted experimental observations, and so whoever retained it correct would be justified (Baliani, 1646: p. 113).

Paolo Galluzzi maintained that Baliani was not particularly original in his approach that could be completely derived from that of Fabri (Galluzzi, 2001: pp. 265-270). Actually it must be said that on this matter it is very difficult to pose a question of priority. Fabri was not the first to propose a mathematical law based on the impetus; he was preceded at least by Descartes and Beeckman in 1618 (Koyré, 1966: 111; Damerow et al., 1991: pp. 28-29). So any differences between the Tractatus physicus de motu locali and the De motu naturali gravium solidorum et liquidorum, may be so slight as to exonerate Baliani from the accusation of plagiarism.

The modern reader should also to query the originality of Fabri and Baliani with respect to the medieval theory of impetus, supposing they were acquainted with it. The answer is not easy when physical aspects are in question. From a technical point of view, however, the difference is quite clear. Medieval theory were not explicit regarding whether impetus should accumulate with time or with space and the difference between the two cases was not clear. Fabri and Baliani, as they came after Galileo, clearly assumed that impetus accumulates with time. Moreover, the development of mathematics with the emerging concept of indivisibles and infinitesimals furnished a powerful formal apparatus.

\section{Writings on the Philosophy of Nature}

Not many writings of Baliani remain. From his correspondence with the Jesuit 
mathematician Gio Luigi Confalonieri (c. 1600-1653) we know, however, that Baliani expressed his interest in this area much earlier than the publication of the De motu gravium solidorum of 1638. In January 1639 he wrote a letter to Confalonieri stating that he prepared a note on the nature of light "many years before" (Costantini, 1969: p. 54). Still in September 1639, writing to Bonaventura Cavalieri (1598-1647), Baliani wrote:

Though I made some study in mathematics, my interest is rather in finding effects and causes of natural things, of which I always thought that we know little if we do not have the support of mathematics, which guarantees the truth. Thus I tried to use it. Anyway I never estimated that philosophical matters do not depend on philosophical principles (Moscovici, 1967: p. 204).

Baliani did not find time to publish a full treatise of natural philosophy. He limited himself, in 1647, to write the less demanding Trattato di Gio. Battista Baliano della pestilenza: ove si adducono pensieri nuovi in più materie (herein after Trattato della pestilenza), that although officially devoted to the plague, dealt with arguments of natural philosophy, and given its nature permitted a less rigorous treatment of philosophical matters.

The treatise was divided into two books; the first book is titled: Of the nature of the plague (pp. 1-153), the second book is titled: It is likely that contagion only cannot cause the plague (pp. 155-198). From the general title and those of the two books, he would appear to be dealing with a medical textbook. Actually, it was not the case, and could not be so, because Baliani was not a physician. Certainly, the topic of the plague was quite central, and particularly so in the second book, and it was also the one which ensured the success of the text, because the subject of the plague was faced for the first time with scientific method and reference to modern conceptions of natural philosophy. However, most of the text, and almost all of the first book, covered topics of natural philosophy. In particular, they dealt with topics which were then classified as meteorological, in line with the Aristotelian tradition of Meteorologica, along with elements of biology and botany. The treatise was equipped with a good index.

The most general aspects of Baliani's epistemology expressed in the Trattato della pestilenza are the superiority of the method more geometrico and the refusal of authority. In the preface of his treatise Baliani talked at length on the superiority of the application of the method more geometrico to any subject:

Indeed, in my youth, spending most of my time in my study, I read many books, in any field, but without remaining completely satisfied in most cases. Devoting myself more carefully to mathematics, I felt I began to understand and know what knowledge actually is and how the intellect is delighted less with the opinion and more with the science (Baliani, 1653: Preface, not numbered pages).

The adoption of the method more geometrico for Baliani did not however imply applying mathematics to philosophy. Baliani here followed Aristotelian 
epistemology, by adapting it to his purpose, according to which any science has its own principles:

Based on this truth I strived to distinguish, to the extent that I could, in any branch of learning, certain things from uncertain ones [...] By reducing the discourse to syllogisms, in any of every [discourse] the major premise will be one of such propositions that are naturally known by everybody, the medium premise depends on postulates in mathematics, revelation in theology and experience in philosophy (Baliani, 1653: Preface, not numbered pages).

where "philosophy" should be intended as natural philosophy; in this field the philosopher should only base on experience and deduction.

The rejection of the appeal to authority is expressed effectively in the first book:

It may seem that I was not told that to prove my argument I did not refer to the authority of great men, who stated this before me; and whether I knew [the authority], I would have not expressed it, estimating as an abuse, to prove [something] with other than by reason, which in natural things is based on experience; and to whom has some authority on his side, should suffice to have someone who furnishes further arguments (Baliani, 1653: p. 97).

Baliani at no time made any reference to the approach of mixed sciences. This appears surprising considered that in his books on motion and in other writings he wrote on various matters such as those regarding atmospheric pressure, the mechanism of tides, the astronomical hypotheses where he sought to follow in Galileo's footsteps in reading the mathematical characters of the book of nature.

Even a superficial reading of the Trattato suggests analogies with Baliani's treatise of the plague and Cabeo's commentary on Metereologica. The subject matter is similar, though the treatment of particular aspects is different. There is the same disdain toward authority, the corpuscular conception of matter, the search for efficient causes of all phenomena, the lack of any use of mathematics.

Baliani better specified his ideas on natural philosophy in the Dialogo secondo of his Operediverse (Baliani, 1666: pp. 39-57). Here he maintained that the approach of mathematics could be of some help to philosophy not only given its deductive arguing, but also because it requires a rigorous analysis of its principles. These should be absolutely sure and derived from empirical evidence, he stated. In this way, any controversy among philosophers could be avoided and philosophy would cease to be conjecture and become exact as mathematics.

To this purpose, he criticized the Aristotelian theory of elements, as it is not directly derivable from the experience, and suggested the approach followed by chemists (chimici) that made the "autopsy" to the matter. He also specified that the first principles of matter are water, earth and light and declared that he could base a philosophy on them which had the same certitude as mathematics, where 
consequences are deduced by means of syllogisms from certain principles.

Various are the casts of mind, so that one considers as true for a reason, another [considers] as false for another [reason]. [...] if, instead, there were greater moderation and people accustomed to know with more moderation and to distinguish what is known from what is unknown, it is certain that wise men would be in agreement with things of which there would be exact knowledge (Baliani, 1666: pp. 43-44).

It is thus clear that Baliani has maintained throughout his life the same basic epistemological assumption: the principles of philosophy should be based on experience and experiments, which are infallible in themselves.

\section{Conclusions}

Baliani had a significant role in the theory of mechanics during the second half of the 17th century. The scope of this article is to highlight his epistemology. It should be placed in the transition period between the old mixed mathematics, that for philosophers harked back to Aristotle's foundational theories of epistemology, involving confined areas of the philosophy of nature, and modern mathematical physics that tries to comprehend the philosophy of nature as a whole. Any study of Baliani is interesting in that, as a fairly good philosopher, he explicitly expressed his epistemological conceptions, not without some contradictions, however. The 1638 text in my opinion is Baliani's most interesting writing, positioned within the framework of classical mixed mathematics, containing among the principles propositions belonging to natural philosophy that should be seen as undoubtedly resulting from sense observations. Baliani introduced an important variant: the undeniable truths of the propositions of the philosophy of nature should not be derived from daily observations, as suggested by Aristotelian epistemology and partly attested by the practice of mixed mathematics, astronomy excluded. The propositions considered as indubitable should stem from careful observations conducted in the laboratory with the aid of measuring instruments, clocks and graduated rulers.

The results reported in De motu gravium solidorum of 1638 were well received in the international arena, in a period when the Galilean theory of falling bodies was not universally shared. Certainly, the simultaneous issue of the Discorsi e dimostrazioni matematiche sopra due nuove scienze by Galileo overshadowed Baliani's merit. He discussed his epistemological approach and his results with Galileo, defending the originality and merits of the former and priority of the latter.

As often happens in the history of science, in order to generalize and improve his exposures, in 1646 Baliani published an expanded edition of the 1638 text, De motu gravium solidorum et liquidorum, where he reported a very interesting discussion of the motion of fluids, that, to my knowledge, remains largely unexamined by historians of science. In this text Baliani overturned his empiricist approach, asserting that the observations based on experimental measurements 
could not be taken as principles of science affected as they are by measurement errors and, therefore, not indubitable. Thus other principles should be searched for that belong to natural philosophy, but have a metaphysical and not an empirical derivation. Baliani's principles were quite simple: the constancy of the action of gravity and the persistence of acquired motion. Perhaps these too could be derived from the senses, but Baliani did not and left the modern reader to face the contradictions. On the one hand, he supported empiricist philosophy that required the assumption of certain principles derived from experience. He expressed this epistemological position both in his approach to mixed mathematics in 1638 and in his writings on the philosophy of nature found in the treatise on the plague and in his philosophical dialogues. On the other hand, though limited to the laws of motion, he declared the groundlessness, at least from a theoretical point of view, of a purely empirical approach and wanted to assume propositions not directly derivable from empirical observations as the principles of the philosophy of nature.

\section{References}

Baliani, G. B. (1638) De motugraviumsolidorum. Geonoa: Farroni et al.

Baliani, G. B. (1646). De motu gravium solidorum et liquidorum. Geonoa: Farroni et al.

Baliani, G. B. (1653). Trattato di Gio. Battista Baliano della pestilenza: Ove si adducono pensieri nuovi in più materie. Genoa: Guasco.

Baliani,G. B. (1666). Di Gio. Battista Baliani opere diverse. Geonoa: Calenzani.

Baroncelli, G. (1998). De motu naturali gravium solidorum et liquidorum. Florence: Giunti.

Cabeo, N. (1646). In quatuor libros meteorologicorum Aristotelis commentaria. Rome: Corbelletti.

Capecchi, D. (2013). Experiments and Principles of Natural Philosophy in Baliani's Epistemology. Proceedings of 33rd SISFA. Acireale, in Press.

Capecchi, D. (2014). A Treatise on the Plague by Giovanni Battista Baliani (pp. 47-55). Proceedings of 34 th SISFA. Florence.

Capecchi, D. (2015). The Problem of Motion of Bodies. Dordrecht: Springer.

Cardinali, F. (1823). Nuova raccolta d'autori italiani che trattano del moto dell'acque. In G. Galilei (1890) (Ed.). Le opere di Galileo Galilei (Vol. 13, pp. 348-349).

Caverni, R. (1891). Il metodo sperimentale in Italia (6 vols). Florence: Civelli.

Costantini, C. (1969). Baliani e i Gesuiti. Florence: Giunti.

Damerow, P., Freudenthal, G., Mclaughlin, P., \& Renn, J. (1991). Exploring the Limits of Pre-Classical Mechanics. New York, NY: Springer.

De Pace, A. (1993). Le matematiche e il mondo. Milan: Francoangeli.

Dear, P. (1995). Discipline \& Experience. Chicago, IL: The University of Chicago Press. https://doi.org/10.7208/chicago/9780226139524.001.0001

Drake, S. (1967). A Seventeenth-Century Malthusian. Isis, 58, 401-402. https://doi.org/10.1086/350274

Galilei, G. (1890). Le opere di Galileo Galilei (National ed., 20 vols). Florence: Barbera.

Galluzzi, P. (2001). Gassendi and l'Affaire Galilée of the laws of motion. Science in Context, 14, 239-275. https://doi.org/10.1017/S0269889701000369 
Koyré, A. (1953). An Experiment in Measurement. Proceedings of the American Philosophical Society, 97, 222-237.

Koyré, A. (1966). Études Galiléennes. Paris: Hermann.

Lavaggi, A. (2004). Attività e propensioni scientifiche in Liguria nei secoli XVI e XVII. Balbisei. Ricerche Storiche Genovesi, 1, 93-115.

Maffioli, C. (2011). La ragione del vacuo: Why and how Galileo measured the resistance of vacuum. Galileana, 8, 73-100.

Matthews, M. R. (2000). Time for Science Education. New York, NY: Kluwer. https://doi.org/10.1007/978-94-011-3994-6

Moscovici, S. (1960). Sur l'incertitude des rapports entre experience et theorie au 17e siècle: La loi de Baliani. Physis, 2, 14-43.

Moscovici, S. (1965). Les développements historiques de la théorie galiléenne des marées. Revue d'Histoire des Sciences et de leurs Applications, 18, 129-240. https://doi.org/10.3406/rhs.1965.2415

Moscovici, S. (1967). L'expérience du mouvement. Jean-Baptiste Baliani disciple et critique de Galilée. Paris: Hermann.

Nonnoi, G. (1988). Il pelago d'aria. Rome: Bulzoni.

Riccati, V. (1757). Opusculorum ad res physicas, \& mathematicas pertinentium. Bologna: Volpe.

Savelli, R. (1953). Giovan Battista Baliani e la natura della luce. Bologna: Tipografia Compositori.

Somaglia, A. (1983). Il lume di G.B. Baliani. In Storia delle matematiche in Italia. Istituti di matematica delle facoltà di scienze e ingegneria (pp. 395-403). Cagliar: Università di Cagliari.

Zouckermann, R. (1982). Poids de l'air et pression atmosphérique. Physis, 24, 133-156.

\section{Submit or recommend next manuscript to SCIRP and we will provide best service for you:}

Accepting pre-submission inquiries through Email, Facebook, LinkedIn, Twitter, etc. A wide selection of journals (inclusive of 9 subjects, more than 200 journals) Providing 24-hour high-quality service User-friendly online submission system Fair and swift peer-review system Efficient typesetting and proofreading procedure Display of the result of downloads and visits, as well as the number of cited articles Maximum dissemination of your research work

Submit your manuscript at: http://papersubmission.scirp.org/

Or contact ahs@scirp.org 